\title{
BMJ Open Education level and health-related quality of life after oesophageal cancer surgery: a nationwide cohort study
}

\author{
Anna Regina Schandl, Asif Johar, Kalle Mälberg, Pernilla Lagergren
}

To cite: Schandl AR, Johar A, Mälberg K, et al. Education level and health-related quality of life after oesophageal cancer surgery: a nationwide cohort study. BMJ Open 2018;8:e020702. doi:10.1136/ bmjopen-2017-020702

- Prepublication history and additional materials for this paper are available online. To view these files, please visit the journal online ( http://dx.doi. org/10.1136/bmjopen-2017020702).

Received 24 November 2017 Revised 13 July 2018 Accepted 13 July 2018

\section{ABSTRACT}

Objective The purpose of the study was to investigate whether low education level was associated with patients' health-related quality of life (HRQOL) after oesophageal cancer resection.

Setting A nationwide cohort study in Sweden. Participants In total, 378 patients who underwent oesophageal cancer surgery in 2001-2005 were followed up 6 months and 3 years after surgery.

Outcome measures HRQOL was assessed by the European Organisation for Research and Treatment of Cancer Quality of Life Questionnaire-Core 30 (QLQ-C30) and the oesophageal cancer-specific module. The association between level of education and HRQOL was calculated with linear regression models, providing mean score differences (MD) and 95\% Cls. Data were analysed separately for women and men.

Results Education level was not associated with HRQOL recovery after oesophageal cancer surgery. However, when data were stratified by sex, lower education was associated with worse emotional function (MD -13; $95 \% \mathrm{Cl}-22$ to -3 ), more symptoms of insomnia (MD 20; $95 \% \mathrm{Cl} 8$ to 32) and reflux (MD: 15; 95\% Cl 3 to 26) for women, but not for men. Among women, low education was in general associated with worse functioning and more symptoms.

Conclusions Low education was not associated with worse HRQOL after oesophageal cancer surgery. However, when data were stratified for sex, low education level was associated with worse functioning and more symptoms in certain HRQOL domains for women, particularly in a shortterm perspective. For men, no such association was found.

\section{INTRODUCTION}

Surgical resection is an essential part of curatively intended treatment for oesophageal cancer. ${ }^{1}$ Due to advances in treatment, survival rates have increased during the last decade, which in turn has made health-related quality of life (HRQOL) an even more important and acknowledged outcome measure. ${ }^{2}$ Most patients reach preoperative HRQOL levels 1 year after surgery. ${ }^{3}$ However, a prospective population-based study showed that $50 \%$ of the included patients did not improve in global quality of life between 6 months and 5 years and $17 \%$ deteriorated

\section{Strengths and limitations of this study}

A population-based, nationwide design with high inclusion rate of all eligible patients in Sweden.

- Robust exposure measure reducing the risk of misclassification.

- Limited statistical power to detect weak or moderate differences, particularly in the stratified analysis.

further. ${ }^{4}$ Despite being cured, these patients seem to suffer from debilitating and persistent symptoms even up to 10 years after surgery. ${ }^{5}$ This accentuates the need to identify factors, not associated with the surgery itself, but with person-related issues that may promote or impede HRQOL recovery. Comorbidity may to some degree influence the recovery in HRQOL, ${ }^{6}$ but does not fully explain the long-term HRQOL deterioration. Thus, it still remains unclear what prevents full HRQOL recovery after oesophagectomy. Higher education has been shown to have a beneficial effect on survival for patients with cancer. $^{78}$ For patients with oesophageal cancer, a nationwide study showed that higher level of education was associated with lower mortality rates. ${ }^{9}$ Since education seems to be an important factor for predicting outcome, we hypothesised that low education level is associated with, increased mortality, and reduced HRQOL after oesophageal cancer resection. Moreover, the association of healthcare and HRQOL seems to differ between men and women. ${ }^{10} 11$ Therefore, we also aimed to investigate whether education level influences HRQOL recovery differently for men and women.

\section{METHODS}

Study design

A Swedish nationwide cohort study including patients curatively operated on for oesophageal cancer during a 5-year period 
(2001-2005). Patients were followed up until the end of 2008 , that is, up to 3 years following surgery.

\section{Data collection}

A detailed description of this nationwide data collection has been published elsewhere. ${ }^{12}{ }^{13}$ In brief, the study was based on a nationwide network of 174 Swedish hospital departments with contact clinicians involved in diagnostic procedures or treatment of patients with oesophageal cancer, in which $90 \%$ of eligible patients were included. Information regarding patient and tumour characteristics, treatment, and complications were prospectively collected, and based on a predefined study protocol to ensure completeness and uniformity. Comorbidity was predefined as diabetes, cardiac, respiratory, renal or other specified conditions. ${ }^{14}$ Information about comorbidity was collected from the Swedish Patient Register, which contains all in-hospital diagnoses in Sweden since 1987 and all outpatient specialist care since 2001. Patients' self-reported HRQOL was collected by validated questionnaires at 6 months and 3 years after surgery for oesophageal cancer.

\section{Education level}

Information on education was obtained from the Longitudinal Integration Database for Health Insurance and Labour Market (LISA). LISA holds registration since 1990 and is updated yearly with information on the highest formal education level attained by each Swedish resident. ${ }^{15}$ The highest attained education level at the time of the oesophagectomy was classified into two categories: (1) Higher education, represented by 10 years or more of formal education, including postsecondary education and (2) Compulsory education, which corresponds to 9 years or fewer, including primary and lower secondary education, that is, up to the age of 16 years.

\section{HRQOL assessment}

HRQOL was assessed using two self-administered questionnaires, both developed and validated by the European Organisation for Research and Treatment of Cancer Quality of Life (EORTC). ${ }^{16} 17$ The EORTC Quality of Life Questionnaire-Core 30 (QLQ-C30) consists of 30 items that measure HRQOL aspects in patients with cancer in general. ${ }^{16}$ Questionnaire items are grouped into one global quality of life scale, five function scales (physical, role, emotional, cognitive and social), three symptom scales (fatigue, nausea/vomiting and pain) and six single items (dyspnoea, insomnia, appetite loss, constipation, diarrhoea and financial difficulties). An oesophageal cancer-specific module (OES18), the EORTC QLQ-OES18 was used to assess problems common among patients with oesophageal cancer. ${ }^{17}$ This 18 -item questionnaire consists of four scales (dysphagia, reflux, eating difficulties and oesophageal pain) and six single items (trouble swallowing saliva, choking, dry mouth, coughing, speech difficulties and problems with taste). In both questionnaires, the four response alternatives were: 'not at all', 'a little', 'quite a bit' and 'very much'. The only exception was the items in the global quality of life scale, which had a seven-graded rating, ranging from 1 ('very poor') to 7 ('excellent').

Clinically relevant mean HRQOL differences between groups were handled according to the classification of Osoba et $a l^{18}$ where changes of $\geq 10$ points were considered to be clinically relevant and noticeable for the patients.

\section{Statistical analyses}

Questionnaire responses were linearly transformed into scores between 0 and 100 according to the EORTC manual. ${ }^{19}$ Higher scores in the global quality of life scale and function scales are equivalent to better HRQOL, whereas for symptom scales and individual items, a higher score is interpreted as more symptoms. The association between level of education and HRQOL was calculated with linear regression models, providing mean scores, mean score differences (MD) and 95\% CIs. High education was used as reference. The analyses were performed separately for 6 months and 3 years and further stratified for men and women. The multivariable regression model was adjusted for age $(<60,60-75$ or $<75$ years $)$, sex, number of comorbidities $(0, \geq 1$ according to the Charlson Comorbidity Index ${ }^{20}$ ), tumour stage (0-I, II, III, IV) and tumour histology (squamous cell carcinoma or adenocarcinoma) tumour location (upper/middle, lower oesophagus or cardia), body mass index $\geq 25 \mathrm{~kg} / \mathrm{m}^{2}$ and complications within 30 days of surgery (yes or no). A difference of $\geq 10$ mean HRQOL scores between education groups was regarded as clinically relevant ${ }^{18}$ and statistical significance was tested (with two-tailed test and $5 \%$ level of significance where no adjustments for multiple testing were made) only when the MDs were clinically relevant. An experienced senior biostatistician (AJ) conducted all data management and statistical analysis according to a predefined study protocol (online supplementary file: study protocol). The statistical software SAS V.9.4 (SAS Institute) was used to all statistical analysis.

\section{Patient involvement}

Patients and public were not involved in the design of the study. Findings from this study will be communicated to patients and healthcare professionals through conferences and patient meetings.

\section{RESULTS \\ Patients}

During the study period, 614 patients underwent oesophageal cancer surgery. Of these patients, 490 survived for at least 6 months, and 401 patients (82\%) completed the HRQOL questionnaires. Twenty-three patients were excluded due to missing data. Thus, 378 patients $(75 \%)$ were included in the study. Among the included patients, 209 survived for 3 years, of whom 172 (82\%) completed the 3-year follow-up questionnaires. Patient, tumour and 
therapy characteristics were similar between responders and non-responders (online supplementary file table 1A, B). Deaths did not differ by gender or by education level (data not shown).

For the 6-month survivors, 174 patients $(46 \%)$ had compulsory education corresponding to 9 years or fewer and 204 patients $(54 \%)$ had attained a higher education. Patient characteristics were similar between the groups except that patients with lower education were generally older at the time of surgery and had greater comorbidity (table 1).

For the 3-year survivors, 78 patients (45\%) had a compulsory education only. Patient and tumour characteristics were comparable for the two groups except for that patients with lower education had more comorbidities (table 2).

\section{Low education level and HRQOL}

Education level did not influence HRQOL recovery at 6 months or 3 years after surgery. Global quality of life, functions, general and oesophageal cancer-specific symptoms were similar between patients with low and high education level with no clinically relevant differences in mean HRQOL scores (table 3).

\section{Education level and short-term HRQOL in women and men}

For patients with low education level, women reported clinically relevant and statistically significantly worse emotional function (MD -13; 95\% CI -22 to -3 ), more symptoms of insomnia (MD 20; 95\% CI 8 to 32) and reflux (MD 15; 95\% CI 3 to 26) compared with men. Among women, low education was associated with clinically relevant and statistically significantly worse emotional function (MD $-22 ; 95 \%$ CI -34 to -11 ), cognitive function (MD $-20 ; 95 \% \mathrm{CI}-30$ to -10$)$ and social function (MD $-14 ; 95 \%$ CI -28 to -1 ) as well as more symptoms of fatigue (MD 14; 95\% CI 1 to 26), pain (MD 21; $95 \%$ CI 7 to 34 ), insomnia (MD 22; 95\% CI 8 to 36), oesophageal pain (MD 12; 95\% CI 1 to 24) and dry mouth (MD 17; $95 \%$ CI 2 to 32). Among men, low education level was not associated with reduced HRQOL (table 4, figures 1 and 2).

\section{Education level and long-term HRQOL in women and men}

Low education level was associated with several clinically relevantly poorer functions and symptoms for women compared with men but only problems with taste was also statistically significant (MD 22; $95 \%$ CI 4 to $40 ; \mathrm{p}$ 0.02 ). For women, low education was associated with clinically and statistically significantly worse role function (MD $-25 ; 95 \% \mathrm{CI}-46$ to -3 ), emotional function (MD -15 ; $95 \%$ CI -30 to 0 ), social function (MD -22 ; $95 \%$ CI -39 to -4 ) and more financial difficulties (MD $17 ; 95 \%$ CI 1 to 32 ) as compared with those with higher level of education. Among men, only appetite loss was found to be clinically significantly worse (MD -12 ; $95 \%$ CI -23 to -1$)$ in those with a low level of education (table 5).
Table 1 Patient, tumour and therapy characteristics of 378 patients 6 months after oesophageal cancer surgery, categorised by education level

\begin{tabular}{|c|c|c|}
\hline & \multicolumn{2}{|l|}{ Education level } \\
\hline & $\begin{array}{l}\text { High ( } \geq 10 \text { years) } \\
\text { No }(\%)\end{array}$ & $\begin{array}{l}\text { Low ( } \leq 9 \text { years) } \\
\text { No }(\%)\end{array}$ \\
\hline Total & 204 & 174 \\
\hline \multicolumn{3}{|l|}{ Gender } \\
\hline Men & $162(79)$ & $145(83)$ \\
\hline Women & $42(21)$ & $29(17)$ \\
\hline \multicolumn{3}{|l|}{ Age at surgery (years) } \\
\hline$<60$ & $68(33)$ & $26(15)$ \\
\hline $60-74$ & $112(55)$ & $108(62)$ \\
\hline$\geq 75$ & $24(12)$ & $40(23)$ \\
\hline \multicolumn{3}{|l|}{ No of comorbidities } \\
\hline 0 & $131(64)$ & $85(49)$ \\
\hline$\geq 1$ & $73(36)$ & $89(51)$ \\
\hline \multicolumn{3}{|l|}{ Body mass index $\left(\mathrm{kg} / \mathrm{m}^{2}\right)$} \\
\hline$\geq 25$ & $104(51)$ & $82(47)$ \\
\hline$<25$ & $100(49)$ & $92(53)$ \\
\hline \multicolumn{3}{|l|}{ Tumour histology } \\
\hline $\begin{array}{l}\text { Squamous cell } \\
\text { carcinoma }\end{array}$ & $44(22)$ & $43(25)$ \\
\hline Adenocarcinoma & $160(78)$ & $131(75)$ \\
\hline \multicolumn{3}{|l|}{ Tumour location } \\
\hline $\begin{array}{l}\text { Upper/middle } \\
\text { oesophagus }\end{array}$ & $26(13)$ & $30(17)$ \\
\hline $\begin{array}{l}\text { Lower oesophagus or } \\
\text { cardia }\end{array}$ & $178(87)$ & $144(83)$ \\
\hline \multicolumn{3}{|l|}{ Pathological tumour stage } \\
\hline $0-1$ & $48(24)$ & $31(18)$ \\
\hline II & $62(30)$ & $52(30)$ \\
\hline III & $76(37)$ & $78(45)$ \\
\hline IV & $18(9)$ & $13(7)$ \\
\hline \multicolumn{3}{|l|}{ Neoadjuvant therapy } \\
\hline No & $191(94)$ & $164(94)$ \\
\hline Yes & $13(6)$ & $10(6)$ \\
\hline \multicolumn{3}{|l|}{ Surgical approach } \\
\hline Transthoracic & $173(85)$ & $146(84)$ \\
\hline Transhiatal & $31(15)$ & $28(16)$ \\
\hline \multicolumn{3}{|c|}{ Postoperative complications } \\
\hline No & $139(68)$ & $116(67)$ \\
\hline Yes & 65 (32) & $58(33)$ \\
\hline
\end{tabular}

\section{DISCUSSION}

In this nationwide study on patients with oesophageal cancer treated with surgery, low education was not associated with worse HRQOL in the short or the long term for the total group. However, in women, low education was 
Table 2 Patient and tumour characteristics and healthrelated quality of life 3 years after oesophageal cancer surgery $(n=172)$, categorised by educational level

Education level

High ( $\geq 10$ years) Low ( $\leq 9$ years) No $(\%) \quad$ No $(\%)$

\begin{tabular}{lll}
\hline Total & 94 & 78 \\
Gender & & \\
$\quad$ Men & $73(78)$ & $63(81)$ \\
$\quad$ Women & $21(22)$ & $15(19)$ \\
Age at surgery (years) & & \\
$<60$ & $28(30)$ & $16(21)$ \\
$60-74$ & $58(62)$ & $50(15)$ \\
$\geq 75$ & $8(9)$ & $12(15)$ \\
No of comorbidities & & \\
0 & $59(63)$ & $35(45)$ \\
$\geq 1$ & $35(37)$ & $43(55)$
\end{tabular}

Body mass index $\left(\mathrm{kg} / \mathrm{m}^{2}\right)$

$\begin{array}{lll}\geq 25 & 54(57) & 38(49) \\ <25 & 40(43) & 40(51) \\ \begin{array}{l}\text { Tumour histology } \\ \begin{array}{l}\text { Squamous cell } \\ \text { carcinoma }\end{array}\end{array} & 16(17) & 23(29) \\ \text { Adenocarcinoma } & 78(83) & 55(71)\end{array}$

Tumour location

$\begin{array}{lll}\begin{array}{l}\text { Upper/middle } \\ \text { oesophagus }\end{array} & 9(10) & 14(18) \\ \begin{array}{l}\text { Lower oesophagus or } \\ \text { cardia }\end{array} & 85(90) & 64(82)\end{array}$

Pathological tumour stage

\begin{tabular}{lcc} 
O-I & $44(47)$ & $26(33)$ \\
II & $25(27)$ & $31(40)$ \\
III & $21(22)$ & $17(22)$ \\
IV & $4(4)$ & $4(5)$ \\
Neoadjuvant therapy & & \\
No & $91(97)$ & $77(99)$ \\
Yes & $3(3)$ & $1(1)$ \\
Surgical approach & \\
Transthoracic & $72(77)$ & $66(85)$ \\
Transhiatal & $22(23)$ & $12(15)$ \\
Postoperative complications & \\
No & $62(66)$ & $50(64)$ \\
Yes & $32(34)$ & $28(36)$ \\
\hline
\end{tabular}

associated with worse functioning and more symptoms in certain domains.

The nationwide data collection contributes to strengthening the validity of the results. The exposure measure, education level, was used as a proxy for socioeconomic position. Education level is relevant to people regardless of age or working circumstances, a relatively robust measure and easy to assess. ${ }^{21}$ Information about education level was collected from a database that contains valid and updated information on education for all Swedish citizens, which reduces the risk of misclassification. However, other variables such as income, occupational or marital status may also be of importance for HRQOL recovery but were not included in this study.

A limitation of the study is the lack of preoperative HRQOL data. Still, using preoperative baseline data to measure recovery in HRQOL entails inherent flaws since at such a time, patients' HRQOL is typically highly influenced by the disease itself and psychological factors.

The participation rate was $75 \%$ which could potentially have induced selection bias in the study. However, the non-responders did not differ in characteristics from the participants, and therefore, it is not likely that non-participation would be due to education level. The study was not powered to detect weak or moderate differences in the subgroup analyses. There is a known male predominance in oesophageal cancer, ${ }^{22}$ and when stratifying data by gender, the group of remaining women was relatively small. To increase the statistical power, especially for the 3-year data and for subgroup analyses, a binary classification of the variable for education level was used. Using a more refined categorisation would have enabled an interpretation about the social gradient which the present results do not allow. To reduce the risk of multiple testing and chance findings, we only tested for statistical significance when a clinical relevant difference was reached. The choice of cut-off for such clinical significance was based on previous research. ${ }^{18}$ Available research on clinical significance levels is based on the core QLQ-C30 questionnaire $^{23}$ and since the current study also included a disease-specific module the same cut-off was used for all scales and items. ${ }^{18}$ In this study, patients had survived oesophageal cancer surgery for 3 years that may have lowered their standards of expectations of HRQOL. This response shift may have influenced the results, ${ }^{24}$ but is not likely to have induced differences between groups. The data collection of the study ended in 2008; even though this is not the most recent, there is no reason to believe that education level has less influence on HRQOL today compared with some years ago. However, the treatment of patients with oesophageal cancer has developed during the last decade, for example, today perioperative oncological therapy is often included in the treatment. This may influence the generalisability of the results.

Previous studies have shown an inverse relationship between education level and HRQOL for patients with different diagnoses. ${ }^{25-28}$ In this study, no such association was found until data were stratified by sex. The male predominance in patients with oesophageal cancer may have contributed to mask any gender-specific finding. HRQOL may be perceived differently by men and women ${ }^{10} 11$ and it seems likely that experiences of being diagnosed with cancer and undergoing an extensive surgical procedure follow the same pattern. Studies 
Table 3 Mean score differences with $95 \%$ Cls in HRQOL between patients with high education level ( $\geq 10$ years) versus low education level ( $\leq 9$ years) 6 months and 3 years after oesophageal cancer surgery

\begin{tabular}{|c|c|c|c|c|}
\hline \multirow[b]{4}{*}{ HRQOL aspect } & \multicolumn{4}{|c|}{ Level of education } \\
\hline & \multicolumn{2}{|l|}{ Six months } & \multicolumn{2}{|l|}{ Three years } \\
\hline & $\begin{array}{l}\text { High } \\
\text { (reference) }\end{array}$ & Low & $\begin{array}{l}\text { High } \\
\text { (reference) }\end{array}$ & Low \\
\hline & $\begin{array}{l}\text { Mean scores } \\
(95 \% \mathrm{Cl})\end{array}$ & $\begin{array}{l}\text { Mean differences } \\
(95 \% \mathrm{Cl})\end{array}$ & $\begin{array}{l}\text { Mean scores } \\
(95 \% \mathrm{CI})\end{array}$ & $\begin{array}{l}\text { Mean differences } \\
(95 \% \mathrm{Cl})\end{array}$ \\
\hline \multicolumn{5}{|l|}{ EORTC QLQ-C30 } \\
\hline Global quality of life & 52 (45 to 59 ) & $-3(-8$ to 1$)$ & 59 (45 to 72$)$ & $-2(-9$ to 5$)$ \\
\hline \multicolumn{5}{|l|}{ Functional scales } \\
\hline Physical & 72 (65 to 78$)$ & $-6(-10$ to -2$)$ & 72 (60 to 84$)$ & $-1(-7$ to 6$)$ \\
\hline Role & 56 (45 to 66 ) & $-8(-15$ to -1$)$ & 69 (50 to 89 ) & $-4(-14$ to 6$)$ \\
\hline Emotional & 65 (58 to 73 ) & $-4(-10$ to 1$)$ & 69 (56 to 82 ) & $-5(-12$ to 2$)$ \\
\hline Cognitive & 79 (72 to 86$)$ & $-6(-11$ to -2$)$ & 79 (67 to 91$)$ & $-3(-9$ to 4$)$ \\
\hline Social & 63 (54 to 73 ) & $1(-5$ to 7$)$ & 71 (55 to 87 ) & $-1(-9$ to 7$)$ \\
\hline \multicolumn{5}{|l|}{ Symptom scales } \\
\hline Fatigue & 52 (44 to 60$)$ & 7 (1 to 12$)$ & 35 (19 to 52$)$ & $-2(-10$ to 7$)$ \\
\hline Nausea/vomiting & 24 (17 to 31$)$ & $4(-1$ to 9$)$ & 18 (5 to 32$)$ & $3(-4$ to 10$)$ \\
\hline Pain & 25 (16 to 34 ) & 8 (2 to 14$)$ & 22 (5 to 38 ) & $0(-8$ to 8$)$ \\
\hline \multicolumn{5}{|l|}{ Symptom items } \\
\hline Dyspnoea & 41 (31 to 51$)$ & 5 (-1 to 12$)$ & 43 (25 to 62$)$ & $-2(-11$ to 8$)$ \\
\hline Insomnia & 29 (20 to 39$)$ & 6 (0 to 12) & 36 (16 to 55$)$ & $4(-6$ to 14$)$ \\
\hline Appetite loss & 44 (33 to 58 ) & $4(-3$ to 12$)$ & 35 (15 to 55$)$ & $-8(-18$ to 2$)$ \\
\hline Constipation & 15 (7 to 22$)$ & $4(-1$ to 8$)$ & 16 (2 to 29$)$ & $-2(-9$ to 5$)$ \\
\hline Diarrhoea & 32 (22 to 42$)$ & $4(-2$ to 11$)$ & 32 (13 to 51$)$ & $-5(-14$ to 5$)$ \\
\hline Financial difficulties & 22 (13 to 30$)$ & 6 (1 to 12$)$ & 16 (2 to 29$)$ & 8 (1 to 15$)$ \\
\hline \multicolumn{5}{|l|}{ EORTC QLQ-OES 18} \\
\hline \multicolumn{5}{|c|}{ Disease-specific symptom scales } \\
\hline Dysphagia & 30 (22 to 38$)$ & $-1(-7$ to 5$)$ & 19 (-1 to 39$)$ & $8(-2$ to 18$)$ \\
\hline Reflux & 24 (15 to 33 ) & $4(-2$ to 10$)$ & 21 (3 to 39$)$ & $5(-5$ to 14$)$ \\
\hline Eating difficulties & 44 (36 to 52$)$ & $1(-4$ to 7$)$ & 31 (15 to 47$)$ & $-5(-13$ to 4$)$ \\
\hline Oesophageal pain & 26 (18 to 33 ) & $4(-1$ to 9$)$ & 18 (5 to 32$)$ & $5(-1$ to 12$)$ \\
\hline \multicolumn{5}{|l|}{ Disease-specific items } \\
\hline Trouble swallowing saliva & 17 (9 to 26$)$ & $2(-3$ to 8$)$ & $6(-11$ to 22$)$ & $3(-5$ to 11$)$ \\
\hline Choking & 22 (14 to 31$)$ & $4(-2$ to 9$)$ & 9 (-4 to 23$)$ & $2(-5$ to 9$)$ \\
\hline Dry mouth & 28 (18 to 38$)$ & 8 (1 to 14$)$ & 20 (1 to 39 ) & 1 ( -8 to 11$)$ \\
\hline Coughing & $30(20$ to 40$)$ & $-2(-9$ to 4$)$ & 19 (1 to 36$)$ & $-7(-16$ to 2$)$ \\
\hline Speech difficulties & 21 (13 to 29$)$ & $-1(-6$ to 4$)$ & $11(-1$ to 23$)$ & $0(-6$ to 6$)$ \\
\hline Problems with taste & 32 (22 to 42$)$ & $4(-3$ to 10$)$ & $15(-3$ to 33$)$ & $0(-9$ to 10$)$ \\
\hline
\end{tabular}

The models used to calculate mean scores and mean score differences were adjusted for age, sex, number of comorbidities, tumour stage, tumour histology, tumour location, body mass index $\geq 25 \mathrm{~kg} / \mathrm{m}^{2}$ and postoperative complications. A mean score difference of $\geq 10$ is considered clinically relevant and further tested for statistical significance. EORTC QLQ-C30, European Organisation for Research and Treatment of Cancer Quality of Life Questionnaire-Core 30; HRQOL, healthrelated quality of life; OES 18, oesophageal cancer-specific module.

on psychological aspects have reported that women are more likely to experience physical and emotional symptoms associated with stress and are also more likely to report lower HRQOL life than men. ${ }^{29-31}$ Also, inequalities in socioeconomic status seem to be more important for women than for men, ${ }^{29} 32$ a result that was confirmed by our study. Being in the highest income category and working full time are important predictors for women's 


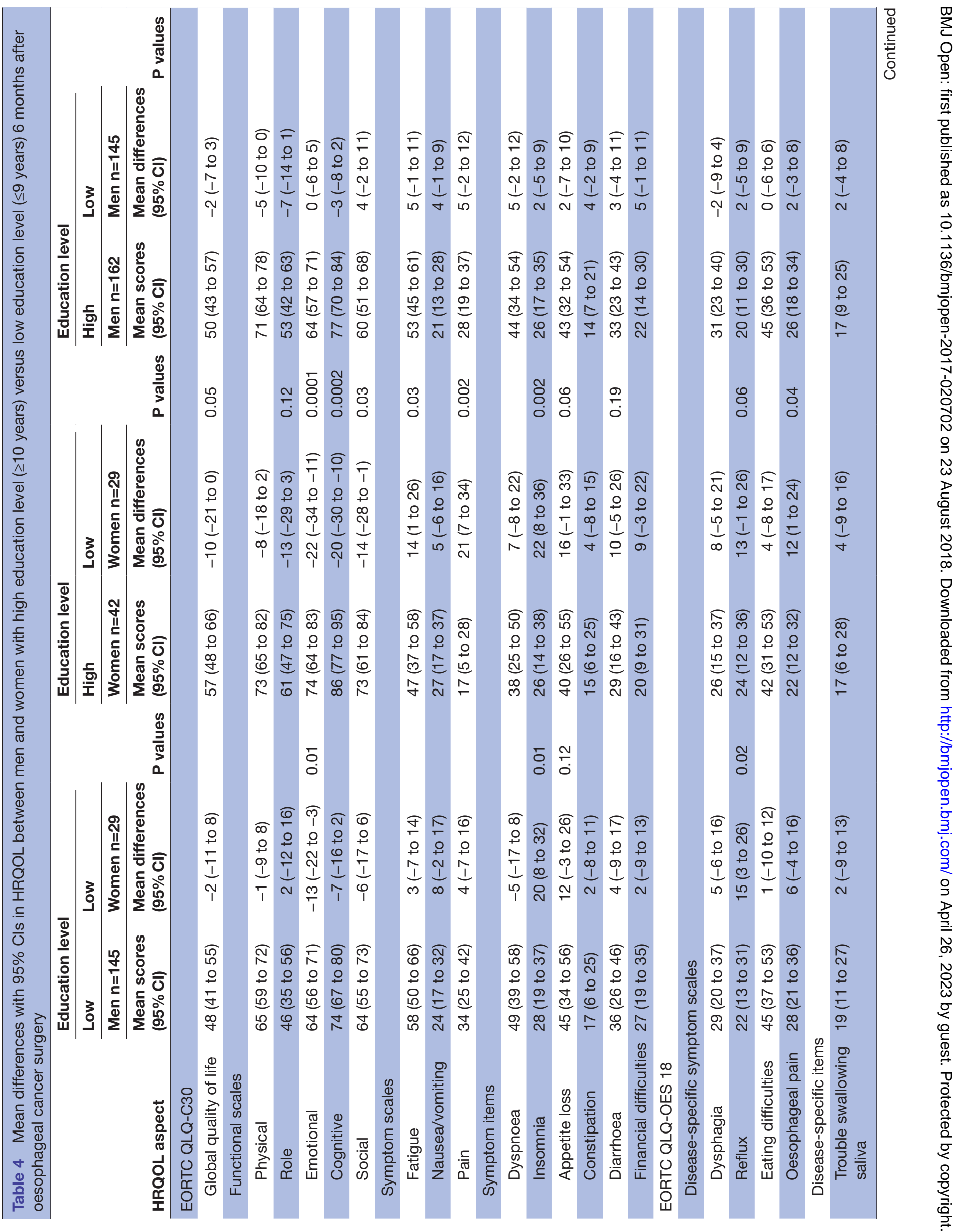




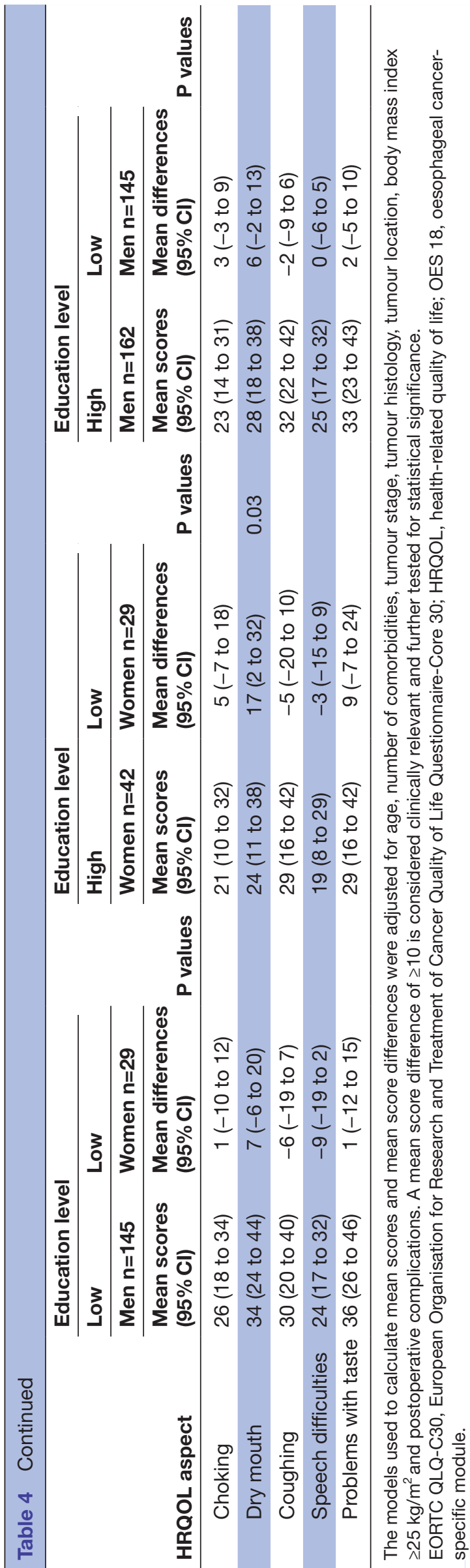

Global quality of life, functional scales, symptom scales and items

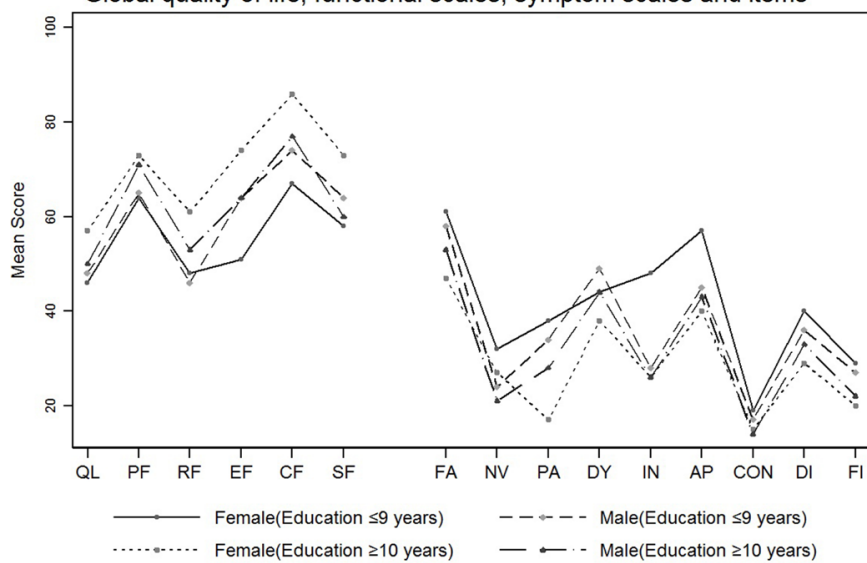

Figure 1 Global quality of life (QL), functional scales, symptom scales and items in men and women with high and low level of education 6 months after oesophageal cancer surgery. In QL and functional scales, high scores indicate better HRQOL. High scores in symptom scales and items correspond to more symptoms. AP, appetite loss; CF, emotional function; CF, cognitive function; CON, constipation; DI, diarrhoea; DY, dyspnoea; EF, emotional function; FA, fatigue; FI, financial difficulties; $\mathrm{HRQOL}$, health-related quality of life; IN, insomnia; NV, nausea/vomiting; PA, pain; PF, physical function; RF, role function; SF, social function.

good health. ${ }^{33-36}$ One possible explanation may be that a higher education level is related to a stronger awareness of the disease and better coping ability with the challenges of a cancer diagnosis. In a study of women with breast cancer, higher education was associated with better coping behaviour. ${ }^{37}$ This information is valuable when designing follow-up strategies after oesophageal cancer surgery. Women with low education level are a vulnerable group of patients who may need intensified support along

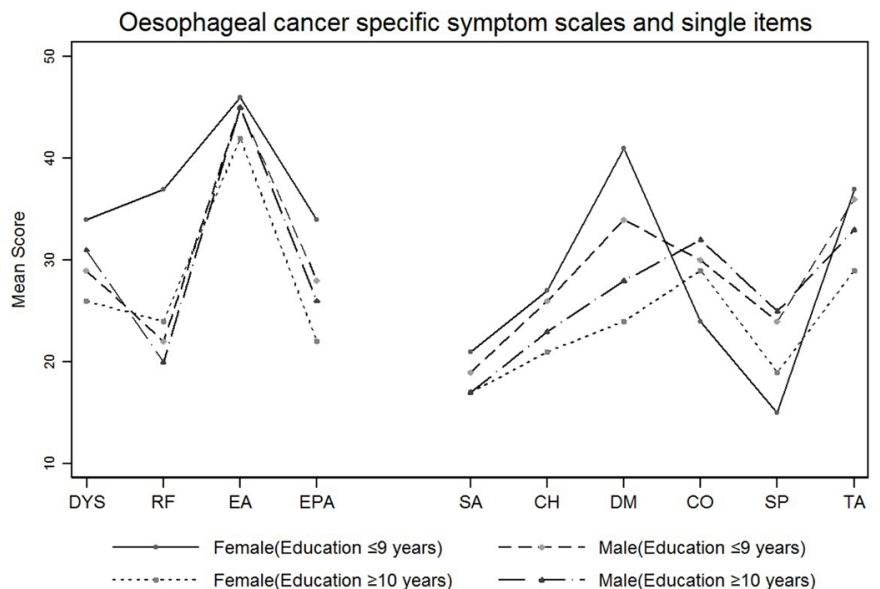

Figure 2 Oesophageal cancer-specific symptom scales and items in men and women with high and low education level 6 months after oesophageal cancer surgery. Higher scores correspond to more symptoms. $\mathrm{CH}$, choking; $\mathrm{CO}$, coughing; DM, dry mouth; DYS, dysphagia; EA, eating difficulties; EPA, oesophageal pain; RF, reflux; SA, trouble swallowing saliva; $\mathrm{SP}$, speech problems; TA, problems with taste. 


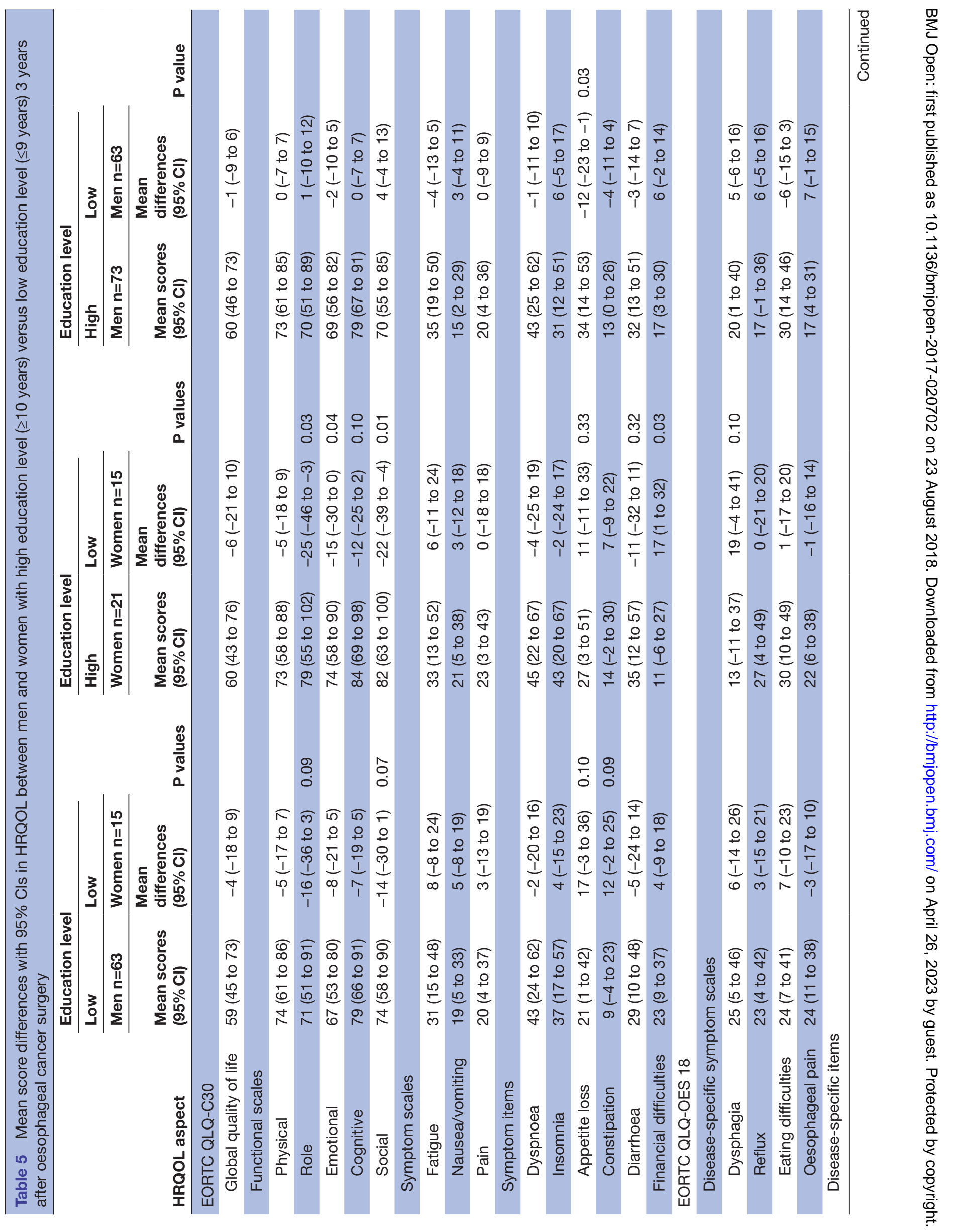


the pathway of cancer survivorship to obtain an optimal recovery in HRQOL.

\section{CONCLUSION}

In this nationwide study, low education was not associated with worse HRQOL after oesophageal cancer surgery. However, when data were stratified for sex, low education level was associated with worse functioning and more symptoms in certain HRQOL domains for women. Based on the results of this study, future cancer survivorship research would benefit from including a gender perspective on HRQOL.

Acknowledgements We would like to acknowledge all the patients who graciously participated in the study.

Contributors ARS, AJ, KM and PL contributed with input in designing the study. Data collection and assembly of data were performed by PL. Data analysis was conducted by AJ. All authors (ARS, AJ, KM and PL) contributed in interpreting the results, manuscript writing and approval of the final version of the manuscript.

Funding This work was supported by the Swedish Cancer Society (Grant number: 140323) and the Cancer Research Foundations of Radiumhemmet (Grant number: 141223).

Disclaimer The funding sources had no role in the design and conduct of the data collection, management, analysis and interpretation of the data or preparation review or approval of the manuscript.

Competing interests None declared.

Patient consent Obtained.

Ethics approval The study is approved by the Regional Ethical Review Board, Stockholm, Sweden.

Provenance and peer review Not commissioned; externally peer reviewed.

Data sharing statement All data underlying the findings are presented in the manuscript. The original database is not accessible through public repository, but available from the Swedish Esophageal and Cardia Cancer Registry at Karolinska Institutet, whose authors may be contacted at pernilla.lagergren@ki.se.

Open access This is an open access article distributed in accordance with the Creative Commons Attribution Non Commercial (CC BY-NC 4.0) license, which permits others to distribute, remix, adapt, build upon this work non-commercially, and license their derivative works on different terms, provided the original work is properly cited, appropriate credit is given, any changes made indicated, and the use is non-commercial. See: http://creativecommons.org/licenses/by-nc/4.0/.

\section{REFERENCES}

1. Rouvelas I, Zeng W, Lindblad M, et al. Survival after surgery for oesophageal cancer: a population-based study. Lancet Oncol 2005;6:864-70.

2. Burkett VS, Cleeland CS. Symptom burden in cancer survivorship. J Cancer Surviv 2007;1:167-75.

3. Parameswaran R, McNair A, Avery $\mathrm{KN}$, et al. The role of healthrelated quality of life outcomes in clinical decision making in surgery for esophageal cancer: a systematic review. Ann Surg Oncol 2008;15:2372-9.

4. Derogar M, Lagergren P. Health-related quality of life among 5-year survivors of esophageal cancer surgery: a prospective populationbased study. J Clin Oncol 2012;30:413-8.

5. Schandl A, Lagergren J, Johar A, et al. Health-related quality of life 10 years after oesophageal cancer surgery. Eur J Cancer 2016;69:43-50.

6. Backemar L, Wikman A, Djärv T, et al. Co-morbidity after oesophageal cancer surgery and recovery of health-related quality of life. Br J Surg 2016;103:1665-75.

7. Cavalli-Björkman N, Lambe M, Eaker S, et al. Differences according to educational level in the management and survival of colorectal cancer in Sweden. Eur J Cancer 2011;47:1398-406.

8. Bentley R, Kavanagh AM, Subramanian SV, et al. Area disadvantage, individual socio-economic position, and premature cancer mortality 
in Australia 1998 to 2000: a multilevel analysis. Cancer Causes Control 2008;19:183-93

9. Jemal A, Simard EP, Xu J, et al. Selected cancers with increasing mortality rates by educational attainment in 26 states in the United States, 1993-2007. Cancer Causes Control 2013;24:559-65.

10. Tan S, Duong Dinh TA, Westhofen M. Evaluation of gender-specific aspects in quality-of-life in patients with larynx carcinoma. Acta Otolaryngol 2016;136:1201-5

11. Wessels H, de Graeff A, Wynia K, et al. Gender-related needs and preferences in cancer care indicate the need for an individualized approach to cancer patients. Oncologist 2010;15:648-55.

12. Lagergren J, Bergström R, Lindgren A, et al. Symptomatic gastroesophageal reflux as a risk factor for esophageal adenocarcinoma. N Engl J Med 1999;340:825-31.

13. Viklund $\mathrm{P}$, Lindblad M, Lu M, et al. Risk factors for complications after esophageal cancer resection: a prospective population-based study in Sweden. Ann Surg 2006;243:204-11.

14. Djärv T, Derogar M, Lagergren P. Influence of co-morbidity on long-term quality of life after oesophagectomy for cancer. Br J Surg 2014;101:495-501.

15. Statistics Sweden. Yearbook of educational statistics. Utbildningsstatistisk årsbok 2015. Sweden: Statistiska Centralbyrån, 2015.

16. Aaronson NK, Ahmedzai S, Bergman B, et al. The European Organization for Research and Treatment of Cancer QLQ-C30: a quality-of-life instrument for use in international clinical trials in oncology. J Natl Cancer Inst 1993;85:365-76.

17. Blazeby JM, Conroy T, Hammerlid E, et al. Clinical and psychometric validation of an EORTC questionnaire module, the EORTC QLQOES18, to assess quality of life in patients with oesophageal cancer. Eur J Cancer 2003;39:1384-94.

18. Osoba D, Rodrigues $\mathrm{G}$, Myles $\mathrm{J}$, et al. Interpreting the significance of changes in health-related quality-of-life scores. $J$ Clin Oncol 1998;16:139-44.

19. Fayers P, Aaronson N, Bjordal K, et al. The EORTC QLQ-C30 Scoring Manual. 3rd ed. Brussels, Belgium: European Organisation for Research and Treatment of Cancer, 2001.

20. Charlson ME, Pompei P, Ales KL, et al. A new method of classifying prognostic comorbidity in longitudinal studies: development and validation. J Chronic Dis 1987;40:373-83.

21. Galobardes B, Shaw M, Lawlor DA, et al. Indicators of socioeconomic position (part 1). J Epidemiol Community Health 2006;60:7-12.

22. Xie SH, Lagergren J. The Male Predominance in Esophageal Adenocarcinoma. Clin Gastroenterol Hepatol 2016;14:338-47.

23. Cocks K, King MT, Velikova G, et al. Evidence-based guidelines for interpreting change scores for the European Organisation for the
Research and Treatment of Cancer Quality of Life Questionnaire Core 30. Eur J Cancer 2012;48:1713-21.

24. Sprangers MA, Schwartz CE. Integrating response shift into healthrelated quality of life research: a theoretical model. Soc Sci Med 1999;48:1507-15.

25. Klein J, Hofreuter-Gätgens K, Lüdecke D, et al. Socioeconomic status and health-related quality of life among patients with prostate cancer 6 months after radical prostatectomy: a longitudinal analysis. BMJ Open 2016;6.e010968.

26. Patti F, Pozzilli C, Montanari E, et al. Effects of education level and employment status on $\mathrm{HRQ}$ oL in early relapsing-remitting multiple sclerosis. Mult Scler 2007:13:783-91.

27. Pragodpol P, Ryan C. Critical review of factors predicting healthrelated quality of life in newly diagnosed coronary artery disease patients. J Cardiovasc Nurs 2013;28:277-84.

28. Jiang Q, Wang HB, Yu L, et al. Variables associated with patientreported outcomes in persons with chronic myeloid leukemia receiving tyrosine kinase-inhibitor therapy. J Cancer Res Clin Oncol 2017;143:1013-22.

29. Tchicaya A, Lorentz N. Socioeconomic inequalities in health-related quality of life between men and women, 5 years after a coronary angiography. Health Qual Life Outcomes 2016;14:165.

30. Emery CF, Frid DJ, Engebretson TO, et al. Gender differences in quality of life among cardiac patients. Psychosom Med 2004;66:190-7.

31. Ford ES, Mokdad AH, Li C, et al. Gender differences in coronary heart disease and health-related quality of life: findings from 10 states from the 2004 behavioral risk factor surveillance system. $J$ Womens Health 2008;17:757-68.

32. Ghasemi E, Mohammad Aliha J, Bastani F, et al. Quality of life in women with coronary artery disease. Iran Red Crescent Med J 2014;16:e10188.

33. Denton M, Prus S, Walters V. Gender differences in health: a Canadian study of the psychosocial, structural and behavioural determinants of health. Soc Sci Med 2004;58:2585-600.

34. Denton M, Walters V. Gender differences in structural and behavioral determinants of health: an analysis of the social production of health. Soc Sci Med 1999;48:1221-35.

35. László KD, Janszky I, Ahnve S. Income and recurrent events after a coronary event in women. Eur J Epidemiol 2008;23:669-80.

36. Handberg EM, Eastwood JA, Eteiba W, et al. Clinical implications of the Women's Ischemia Syndrome Evaluation: inter-relationships between symptoms, psychosocial factors and cardiovascular outcomes. Womens Health 2013;9:479-90.

37. Drageset S, Lindström TC. Coping with a possible breast cancer diagnosis: demographic factors and social support. J Adv Nurs 2005;51:217-26. 